Gynecologic and

Obstetric Investigation

\title{
Clinical Outcomes among Women with Mucinous Adenocarcinoma of the Ovary
}

\author{
Leslie Stewart Massad ${ }^{a}$ Feng Gao $^{b}$ lan Hagemann ${ }^{c}$ Matthew Powell ${ }^{a}$ \\ ${ }^{a}$ Division of Gynecologic Oncology, Department of Obstetrics and Gynecology, ${ }^{b}$ Division of Biostatistics, and \\ 'Department of Pathology and Immunology, Washington University School of Medicine, St. Louis, USA
}

\section{Key Words}

Ovarian cancer $\cdot$ Mucinous adenocarcinoma $\cdot$ Survival analysis

\begin{abstract}
Background/Aims: Patterns of metastasis and clinical behavior of mucinous ovarian cancers are poorly understood because of their rarity. Methods: A retrospective review of records of women identified with pure mucinous invasive ovarian/tubal/peritoneal cancer during 1992-2012 at one institution. Survival differences were compared using Kaplan-Meier methods with log-rank tests. Results: Among 42 women with mucinous adenocarcinomas, the median age was 55 (range 33-83 years). Most cancers were well differentiated $(n=26,68 \%)$ and in stage $\mathrm{I} / \mathrm{II}(\mathrm{n}=31,74 \%)$. One of 27 women with sampled nodes had nodal metastasis; one additional woman had recurrence in a pelvic node. Most had no visible residual tumor after initial surgery, but of 10 women with stage III/IV cancer and documented residual, 8 had $>2 \mathrm{~cm}$ residual. Except for 1 woman alive with disease at last follow-up, all who had a recurrence died of the disease. Fiveyear survival was $83 \%$ for stage I/II cases but $29 \%$ among stage III/IV cases. Stage was a strong predictor of survival (hazard ratio of death among women with stage III/IV cancer $7.73,95 \% \mathrm{Cl} 2.33-25.66, \mathrm{p}<0.001$ vs. women with stage I/II cancer). Conclusion: Mucinous ovarian cancers have a distinct biology, such that lymphadenectomy for staging is unnecessary and metastatic cancers have poor prognosis.
\end{abstract}

(c) 2015 S. Karger AG, Basel

\section{KARGER}

E-Mail karger@karger.com

www.karger.com/goi

\section{Introduction}

While mucinous adenocarcinomas metastatic to the ovary are relatively common, primary mucinous ovarian adenocarcinomas are a rare but biochemically and genetically distinct subgroup of ovarian epithelial cancers [1, 2]. Advanced cancers are resistant to conventional taxane-platinum combination chemotherapy and are highly lethal; innovative chemotherapeutic and biologic therapies have been recommended [3-7]. The behavior of lowstage mucinous adenocarcinomas is less well understood, although prognosis appears similar to low-stage serous cancer $[7,8]$. Two recent papers found no nodal metastases in surgically staged patients with mucinous ovarian cancer, suggesting that lymphadenectomy may be omitted from conventional surgical staging $[8,9]$.

We set out to review a 20-year single institution experience with mucinous ovarian cancers to elucidate the clinical patterns of metastasis at presentation and longitudinally, as well as to describe the natural history of localized and advanced mucinous ovarian cancer.

\section{Materials and Method}

Cases of primary mucinous ovarian adenocarcinoma were identified from institutional databases. The study was approved by the local institutional review board, which waived the requirement for patient-informed consent because of the retrospective nature of the study. One woman with primary tubal and another 
with primary peritoneal mucinous adenocarcinoma were included. Diagnoses were established by expert gynecologic pathologists but were not reviewed for this study. Records were searched from January 1, 1992, through December 31, 2011; 5 patients diagnosed before 2000 whose charts could not be retrieved also were excluded. All cases were reviewed at a multidisciplinary tumor conference attended by gynecologic pathologists and gynecologic oncologists. Criteria for exclusion included prior or concurrent mucinous adenocarcinoma of a primary site other than ovary, tube, or peritoneum; 1 woman with subsequent cholangiocarcinoma 5 years after diagnosis of a stage I mucinous ovarian cancer was included. Women with concomitant mucinous endometrial cancer were excluded, as were women who received neoadjuvant chemotherapy precluding assessment of primary tumor site. Cases with mixed histologies, including mucinous tumors combined with serous, endometrioid, clear cell, neuroendocrine, and other histologic types were also excluded, just as were cases operated primarily at outside institutions. Tumors of low malignant potential with a component showing frank invasion were included, but microinvasive and intraepithelial carcinomas were excluded. Complete surgical staging including omentectomy, peritoneal biopsies, and pelvic and para-aortic lymphadenectomy was usual institutional practice for all clinically localized ovarian adenocarcinomas during the study period, but cases that were incompletely staged because of limiting comorbidity or clinician preference were included. No threshold count was used to assess the adequacy of lymph node sampling. Women discharged from care with cancer whose deaths were documented within 1 year from outside sources were considered to have died of disease at the date of death.

Charts were first reviewed and data abstracted; then demographic and clinical characteristics of the sample were summarized using descriptive statistics. Overall survival (OS) was defined as the time from diagnosis to death due to any cause; patients alive were censored at the date of last clinical contact. The distribution of OS across clinical stage was described using the Kaplan-Meier product limit method and compared by the log-rank test. Hazard ratio (HR) of death was also estimated using the Cox proportional hazard model. All analyses were performed using SAS 9.2 (SAS, Cary, N.C., USA).

\section{Results}

We identified 42 women with mucinous ovarian adenocarcinomas over 20 years of observation at our institution. The median follow-up was 50.5 months (range 3.3196 months). The median age was 55 (range 33-83 years), with $15(36 \%)$ younger than 50. Preoperatively, the median CA125 level was 35 units/ml (range 8-2,730 units/ $\mathrm{ml}$ ) and the median CEA was 1.6 (range 0.6-78.5). Other characteristics are presented in table 1 .

Most cancers were well differentiated and of low stage (table 1). All but 6 of the 42 cases were unilateral, and those 6 presented with clinically apparent extraovarian disease. The frequency of metastatic disease at various
Table 1. Demographic and medical characteristics of 42 women with mucinous ovarian adenocarcinomas

\begin{tabular}{lc}
\hline Grade & $\mathrm{n}(\%)$ \\
\hline Well differentiated & $26(62)$ \\
Moderately differentiated & $5(12)$ \\
Poorly differentiated & $3(7)$ \\
Not recorded & $8(8)$ \\
Stage & \\
$\quad$ I & $27(14)$ \\
II & $4(10)$ \\
III & $9(21)$ \\
IV & $2(5)$ \\
Laterality & $36(86)$ \\
Unilateral & $6(14)$ \\
Bilateral & \\
Residual after laparotomy & $31(74)$ \\
None visible & $1(2)$ \\
$\quad<1$ cm & $0(0)$ \\
$\quad 1-2$ cm & $9(21)$ \\
Unknown & $1(2)$ \\
\hline
\end{tabular}

Table 2. Metastatic sites at initial staging surgery

Pelvic peritoneum 5

Upper abdominal peritoneum 3

Omentum 8

Appendix* 2

Pelvic lymph nodes ${ }^{\dagger} \quad 0$

Para-aortic lymph nodes $^{\dagger} \quad 1$

* Appendices were removed in 22 women. ${ }^{\dagger}$ Pelvic and paraaortic lymph nodes were sampled in 27 women.

sites is presented in table 2 . The omentum was the most common site of metastasis. Of 27 women who had nodal sampling, only 1 (2\%) had nodal metastasis; she developed a vertebral recurrence and died 12 months after diagnosis despite chemotherapy. One additional woman had a recurrence in a pelvic lymph node.

Most patients had no visible residual disease at the conclusion of initial surgery (table 1), as would be expected, given that most presented with ovary-confined disease. However, of 10 women with stage III/IV cancer and documented residual, only one was left with no visible residual, while one had $<1 \mathrm{~cm}$ residual and $8 \mathrm{had}>2 \mathrm{~cm}$ residual. Of the 2 patients left with no or $<1 \mathrm{~cm}$ residual, one was lost to follow-up and the other died of progressive cancer. 
At last follow-up, 10 (27\%) patients had died of disease, $1(3 \%)$ was alive with disease, $1(3 \%)$ had died of intercurrent illness, and 25 (67\%) were without evidence of disease. The most common site of recurrence was the peritoneum in 7 cases ( $17 \%$ of all cases, $64 \%$ of all recurrent cases). Disease recurred in the lung, brain, pelvic node, liver, and vertebra in 1 patient each. Platinumbased chemotherapy had been given to 18 women, with taxane in 14 . With the exception of 1 woman alive with disease at last follow-up, all women who recurred subsequently died of disease. Few received chemotherapy regimens specifically targeted at mucinous tumors, such as combination irinotecan/capecitabine, but those who did, progressed and died, although in this retrospective study, we could not exclude minor responses or delays in progression.

The survival of women with stages I/II and III/IV mucinous ovarian cancer is presented in figure 1. Stage at presentation was a strong predictor of OS and women with stage III/IV cancer had significantly worse survival (HR 7.73, 95\% CI 2.33-25.66, $\mathrm{p}<0.001$ ). The estimated 5 -year survival for stage I/II cases was $83 \%$ but for stage III/IV cases was only $29 \%$.

\section{Discussion}

The presentation and outcomes of mucinous adenocarcinomas of the ovary are strikingly different from those typical of more common serous ovarian cancers. In contrast to the advanced stage yet reasonable survival with highly chemosensitive disease found with highgrade serous cancers, most women with mucinous cancers had limited disease with excellent outcomes. However, a minority presented with advanced disease or developed recurrences, both of which progressed despite both standard and innovative chemotherapy.

Metastatic patterns of mucinous ovarian cancers also appear distinct from those of more common serous carcinomas and appear to merit an individualized approach to staging. Only $36 \%$ of cases in our series presented before the age of 50, when surgical castration may result in decreased quality of life and morbidity due to premature menopause. While we did not assess ovarian conservation prospectively, no patient with apparently limited disease at laparotomy had cancer found in the contralateral ovary. This suggests that after careful discussion of patients' wishes, ovarian conservation may be acceptable. However, confirmation of our findings is needed before ovarian conservation can be recommended for premeno-

Mucinous Ovarian Cancers Outcomes of Mucinous Ovarian Adenocarcinoma

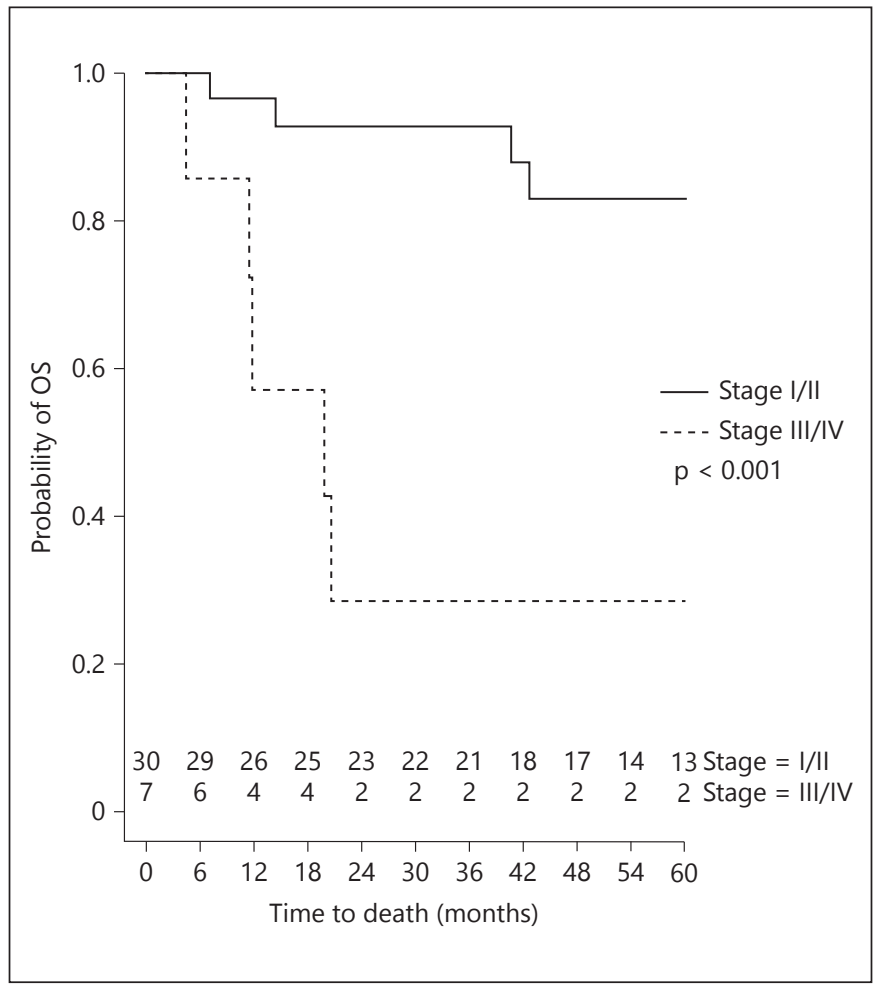

Fig. 1. OS among women with stages I/II and III/IV mucinous ovarian cancers.

pausal women with apparently organ-confined mucinous adenocarcinomas. Bilateral salpingo-oophorectomy would still appear prudent in the face of metastatic disease at other sites.

The yield of lymph node sampling in staging women with mucinous adenocarcinomas is low. In our series, 2 (5\%) patients had nodal metastases, 1 woman a para-aortic node metastasis identified at staging, and another a pelvic node recurrence. In 2 other series of women with ovarian mucinous adenocarcinomas, no patient had nodal metastases $[8,9]$. These results suggest that in the absence of adenopathy, women with suspected mucinous adenocarcinoma can forego nodal sampling. Nodal dissection is sometimes advised for women when malignancy cannot be excluded at intraoperative pathology assessment of masses, but our results and those of others suggest that when pure mucinous tumors are found, lymphadenectomy can be omitted.

With few exceptions, women with mucinous adenocarcinomas in this series fell into 2 classes. Most of those with stage I/II did well, but the stage 11 women who had recurrent episodes and most with initial metastatic disease, progressed and died. This finding is consistent with 
that of Zaino et al. [6], who considered advanced mucinous ovarian cancer highly lethal, and with Mackay and associates, who found that women with advanced mucinous ovarian cancer had a median survival of only 15 months [5]. Optimal debulking was the institutional norm throughout the period reviewed; yet $80 \%$ of women with stage III/IV cancers had $>2 \mathrm{~cm}$ residual, reflecting the extensive, large-volume disease present when mucinous ovarian cancers present at advanced stage. The poor results found in this series after currently available chemotherapy regimens, both those directed at ovarian and those directed at gastrointestinal mucinous cancers, are in line with the findings of Bamias et al. [4], who also found that despite platinum-taxane chemotherapy, women with mucinous ovarian cancers had survival that was poor and significantly worse than that of similar women with serous cancers. Randomized trials of conventional chemotherapy for mucinous ovarian cancer may not be feasible, as reflected in the closure of Gynecologic Oncology Group study \#241 after 3 years with only 16 patients enrolled. However, the poor results with chemotherapy for advanced mucinous ovarian cancer suggest that the identification of innovative targeted therapies that yield prolonged remission would be an important step forward.

Our results were limited by the retrospective nature of the study. Operative notes were not always clear about the extent of disease at abdominal entry, and we cannot assess the utility of peritoneal biopsies of normal-appearing peritoneum in staging. Omentectomy revealed occult metastases in only 2 women in our series. However, the morbidity of omentectomy is small, especially for women with large masses who often have large incisions, and omentectomy appears a prudent component of surgical staging for these women.

In addition, our study was limited by the possibility that some mucinous tumors involving the ovary were in fact metastases from other sites. Assessment for gastrointestinal and other potential alternate primary sites was variable. Poor prognosis for some women with advanced disease-limiting pathologic determination of a primary site may result in some women having a poorer prognosis than those with known primary ovarian mucinous cancer. Because mucinous tumors may arise as a peritoneal field effect, we included women with primary peritoneal and tubal mucinous carcinomas.

The increasingly sophisticated understanding of the genetic and other molecular differences that characterize ovarian cancer subtypes has yet to translate to management guidelines. The National Comprehensive Cancer Network guidelines for ovarian cancer break out strategies for management of women with uncommon histologic types [10], but individuals with mucinous adenocarcinomas are not differentiated from those with other epithelial histologies. In part, this reflects historical evolution, as multicenter prospective trials yielded results dominated by more common serous tumors. Our results, combined with others' findings, suggest evidence-based management for women with mucinous adenocarcinomas is needed. Limited staging including retention of normal-appearing ovaries in premenopausal women and omission of lymphadenectomy appear indicated for women with apparently limited disease. In contrast, focused research is needed to identify potential targets applicable broadly to women with mucinous adenocarcinomas. Meanwhile, women with advanced ovarian mucinous adenocarcinomas may benefit from avoiding multiple rounds of third-line conventional therapy to focus on clinical trials and molecular analysis of their tumors to derive individualized targeted therapies, with an early shift to palliative care in order to maximize quality of life.

\section{Acknowledgment}

The authors wish to acknowledge the support of the Biostatistics Core, Siteman Cancer Center and NCI Cancer Center Support Grant P30 CA091842.

\section{References}

1 Soslow RA: Histologic subtypes of ovarian carcinoma: an overview. Int J Gynecol Pathol 2008;27:161-174.

2 Earp MA, Kelemen LE, Magliocco AM, Swenerton KD, Chenevix-Trench G; Australian Cancer Study; Australian Ovarian Cancer Study Group, Lu Y, Hein A, Ekici AB, Beckmann MW, Fasching PA, Lambrechts D, Despierre E, Vergote I, Lambrechts S,
Doherty JA, Rossing MA, Chang-Claude J, Rudolph A, Friel G, Moysich KB, Odunsi K, Sucheston-Campbell L, Lurie G, Goodman MT, Carney ME, Thompson PJ, Runnebaum IB, Dürst M, Hillemanns P, Dörk T, Antonenkova $\mathrm{N}$, Bogdanova $\mathrm{N}$, Leminen $\mathrm{A}, \mathrm{Ne}$ vanlinna $H$, Pelttari LM, Butzow R, Bunker $\mathrm{CH}$, Modugno F, Edwards RP, Ness RB, du Bois A, Heitz F, Schwaab I, Harter P, Karlan
BY, Walsh C, Lester J, Jensen A, Kjær SK, Høgdall CK, Høgdall E, Lundvall L, Sellers TA, Fridley BL, Goode EL, Cunningham JM, Vierkant RA, Giles GG, Baglietto L, Severi G, Southey MC, Liang D, Wu X, Lu K, Hildebrandt MA, Levine DA, Bisogna $\mathrm{M}$, Schildkraut JM, Iversen ES, Weber RP, Berchuck A, Cramer DW, Terry KL, Poole EM, Tworoger SS, Bandera EV, Chandran U, Orlow I, Olson 
SH, Wik E, Salvesen HB, Bjorge L, Halle MK, van Altena $A M$, Aben KK, Kiemeney LA, Massuger LF, Pejovic T, Bean YT, Cybulski C, Gronwald J, Lubinski J, Wentzensen N, Brinton LA, Lissowska J, Garcia-Closas M, Dicks E, Dennis J, Easton DF, Song H, Tyrer JP, Pharoah PD, Eccles D, Campbell IG, Whittemore AS, McGuire V, Sieh W, Rothstein JH, Flanagan JM, Paul J, Brown R, Phelan CM, Risch HA, McLaughlin JR, Narod SA, Ziogas A, Anton-Culver H, Gentry-Maharaj A, Menon U, Gayther SA, Ramus SJ, Wu AH, Pearce CL, Pike MC, Dansonka-Mieszkowska A, Rzepecka IK, Szafron LM, Kupryjanczyk J, Cook LS, Le ND, Brooks-Wilson A; Ovarian Cancer Association Consortium: Genome-wide association study of subtypespecific epithelial ovarian cancer risk alleles using pooled DNA. Hum Genet 2014;133: 481-497.

3 Kikkawa F, Nawa A, Kajiyama H, Shibata K, Ino K, Nomura S: Clinical characteristics and prognosis of mucinous tumors of the ovary. Gynecol Oncol 2006;103:171-175.

-4 Bamias A, Psaltopoulou T, Sotiropoulou M, Haidopoulos D, Lianos E, Bournakis E, et al: Mucinous but not clear cell histology is associated with inferior survival in patients with advanced stage ovarian carcinoma treated with platinum-paclitaxel chemotherapy. Cancer 2010;116:1462-1468.

5 Mackay HJ, Brady MF, Oza AM, Reuss A, Pujade-Lauraine E, Swart AM, et al; Gynecologic Cancer InterGroup: Prognostic relevance of uncommon ovarian histology in women with stage III/IV epithelial ovarian cancer. Int J Gynecol Cancer 2010;20:945-952.

6 Zaino RJ, Brady MF, Lele SM, Michael H, Greer B, Bookman MA: Advanced stage mucinous adenocarcinoma of the ovary is both rare and highly lethal: a gynecologic oncology group study. Cancer 2011;117:554-562.

7 Schiavone MB, Herzog TJ, Lewin SN, Deutsch I, Sun X, Burke WM, Wright JD: Natural his- tory and outcome of mucinous carcinoma of the ovary. Am J Obstet Gynecol 2011;205:480. e1-e8.

8 Schmeler KM, Tao X, Frumovitz M, Deavers MT, Sun CC, Sood AK, Brown J, Gershenson DM, Ramirez PT: Prevalence of lymph node metastasis in primary mucinous carcinoma of the ovary. Obstet Gynecol 2010;116(2 pt 1): 269-273.

-9 Powless CA, Aletti GD, Bakkum-Gamez JN, Cliby WA: Risk factors for lymph node metastasis in apparent early-stage epithelial ovarian cancer: implications for surgical staging. Gynecol Oncol 2011;122:536540

10 National Comprehensive Cancer Network: NCCN Clinical Practice Guidelines in Oncology: ovarian cancer including fallopian tube cancer and primary peritoneal cancer, version 3, 2014. http://www.nccn.org/professionals/ physician_gls/pdf/ovarian.pdf (accessed July $22,2015)$ 